\title{
IPTEKS ANALISIS SWOT TENTANG PERKEMBANGAN PASAR
} PINASUNGKULAN SAGERAT

\author{
Christian Morgan Moray ${ }^{1}$, Since Rondonuwu ${ }^{2}$ \\ ${ }^{1,2}$ Jurusan Akuntansi, Fakultas Ekonomi dan Bisnis Universitas Sam Ratulangi, Jl. Kampus Unsrat, Manado, \\ 95115, Indonesia \\ Email : morayogan@gmail.com
}

\begin{abstract}
Swot analysis is a problem solving process in determining the best strategy for the progress of the organization by looking at aspects of strengths, weaknesses, opportunities and threats. Swot analysis is accompanied by looking at the efas ifas and swot matrix for measuring the strategy assessment that will be taken. SWOT analysis process by identifying internal factors and external factors by means of data collection and field surveys aimed at obtaining aspects in internal factors and external factors. aspects of strengths and weaknesses are internal because they start from within the organization itself, while aspects of opportunities and threats are included in the external because they originate outside the organization, then the process is continued by connecting internal and external factors in the SWOT matrix to get four strategies, namely how to exploit opportunities, how weaknesses take advantage of opportunities, how strengths minimize threats and how weaknesses and threats seek solutions. from these results can be reflected which strategy is the best to run.
\end{abstract}

Keywords : Strategic planning, evaluate strenghs, evaluate weaknesses, evaluate opportunities, evaluate threats

\section{PENDAHULUAN}

Pasar Tradisional merupakan salah satu tempat dalam bertransaksi antara penjual dan pembeli juga terdapat distirbutor maupun rentinir dalam melakukan usaha mencari keuntungan sekumpulan orang yang melakukan kegiatan transaksi jual-beli. Awal pasar berdiri karena masyarakat ingin mendapatkan sesuatu dalam memenuhi kebutuhan hidup seperti sandang dan pangan, dengan melakukan transaksi tukar menukar hasil bumi atau barang yang di inginkan oleh masyarakat. Proses tukar menukar atau barter bisa di mana saja mengikuti kemauan dari kedua pihak yang ingin melakukan transaksi, penentuan harga juga sesuai kesepakatan selama bertransaksi antara kedua pihak. Seiring perkembangan zaman, proses transaksi mulai telah dilakukan dengan menentukan tempat untuk bertemu nya para penjual dan pembeli dengan acuan harga yang di tawarkan oleh penjual dan bisa ditawar oleh pembeli. Terbentuknya pasar menjadi tongak kemajuan transaksi jual beli oleh masyarakat, didalam pasar terdapat para penjual atau pedagang yang memasarkan dagangan atau produk ke masyarakat dalam mendapatkan keuntungan ada pula pembeli atau konsumen yang datang berbelanja untuk memenuhi kebutuhan hidupnya. Seiring terjadi proses transaksi jual beli di pasar, masyarakat dapat juga melakukan tawar menawar dengan pedagang untuk mendapatkan harga yang pas untuk produk atau barang yang dinginkannya.

Dalam lingkup Pasar Pinasungkulan Sagerat, sering terjadi berbagai transaksi namun karena masih kurang nya minat konsumen dalam berbelanja di Pasar Pinasungkulan Sagerat, telah terjadi ketimpangan terhadap pedagang karena keuntungan pedagang sangat rendah. Pasar Pinasungkulan Sagerat mempunyai luas sekita kurang lebih 6 hektar dengan beberapa fasilitas yang terpisah seperti Tempat berjualan Ikan dan Daging, sayuran, aneka pakain, buah buahan, kios grosir dan banyak fasilitas yang membuat pedagang nyaman. Tetapi itu tidak sesuai harapan karena Pasar Sagerat masih minim daya beli oleh masyarakat. 


\section{TINJAUN PUSTAKA}

Komponen analisis SWOT. Dalam organisasi terdapat kengunggulan dan kelemahan masing masing dapat dilihat dari dua faktor, yakni faktor internal dan faktor eksternal. kekuatan dan kelemahan termasuk dalam faktor internal karena berawal dari dalam organisasi sendiri, sedangkan peluang dan ancaman masuk dalam faktor eksternal karena berawal dari luar organisasi. Dengan tujuan mendapatkan hasil strategi yang terbaik agar bisa dipakai organisasi dalam melayani kebutuhan dan tujuan dari organisasi tersebut. Tujuan dan strategi yang dihasilkan dengan maksud mengunakan kekuatan internal dalam mengantisipasi dan meminimalisir kelemahan organisasi. Terdapat 4 aspek, yaitu:

1. Kekuatan (Strenght) merupakan keunggulan kapasitas dan kemampuan dalam organisasi yang bersangkut paut dengan para pesaing dan kebutuhan pasar yang diharapkan dapat berjalan sesuai dengan target dalam memberikan keunggulan bagi organsisasi pasar.

2. Kelemahan ( Weaknesses) kekurangan dalam kemampuan dan kapasitas dalam organisasi yang berjalan ampuh dalam menghambat pergerakan organisasi pasar. Kekurangan yang terjadi bisa berupa sarana prasana, modal, sumber daya manusia dalam memanajemen organisasi yang menjadikan akar dari kelemahan organisasi pasar.

3. Peluang ( Oppurtunities) kesempatan yang mengguntungkan dalam organisasi pasar yang mengarah terhadap kepentingan kemajuan dalam memaksimalkan probabilitas merupakan alasan terjadi peluang. Kesempatan yang datang seringkali terjadi karena perkembangan globalisasi dan peningkatan transaksi jual beli.

4. Ancaman (Threats) adalah keadaan penting yang merugikan dalam organisasi pasar yang memunculkan resiko dalam perkembangan organisasi pasar. Ancaman timbul karena terjadi gangguan di antara pelaku usaha, pemerintah, masyarakat baik tentang aturan atau perilaku yang semuanya memiliki resiko bahaya tersendiri.

Rancangan pengujian SWOT. Pengujian yang digunakan adalah :

1. Pengambilan data. Proses pendataan dengan menentukan faktor faktor yang mengandung keperluan dalam melakukan penelitian dengan cara mengambil spesimen yang ditentukan dan digarap sebelumnya. Jenis data yang diperoleh ialah data primer dan data sekunder dengan subjek yang didapatkan secara langsung dan tidak langsung. Sesuai sumber yang didapat data internal dan eksternal ialah gambaran dari dalam dan luar organisasi yang diteliti. Data yang di rangkum bisa berbentuk suara, gambar, bahasa dan keadaan dari objek yang diteliti.

2. Turun lapangan dan observasi. Pemantauan dan pengamatan secara langsung untuk menilai keadaan dan mengambil keputusan tentang objek yang di teliti sesuai aspek penilain yang telah dibuat sebelumnya. Hal ini dilakukan agar mendapatkan fakta lapangan yang jelas dan konkrit agar pembuatan penilitian dapat akurat dan bisa menjadi patokan penilain. Dari hasil tersebut juga dapat di pertanggung jawabkan secara sah dan sulit dibantah.

3. Pembuatan data. Penginputan data secara manual dan online dengan teknik pengetikan ke word.doc lalu di upload ke dalam ejournal unsrat melalui beberapa tahapan pengujian.

\section{METODE DAN TEKNIK PENERAPAN IPTEKS}

\subsection{Metode Penerapan Ipteks}

Metode IPTEKS yang diterapakan ialah analisis SWOT dengan rancangan tabel dan grafik matriks. Salah satu prosedur yang dimanfaatkan sebagai alat memilih panduan strategi adalah melalui analisis SWOT dengan beberapa aspek kekuatan, kelemahan, peluang, ancaman untuk pengenalan faktor faktor secara tertata dan teratur dalam merumuskan strategi yang bisa diambil dan diterapkan sesuai porsi yang di inginkan.

\subsection{Teknik Penerapan Ipteks}

Teknik ipteks yang diterapkan adalah analisis SWOT dengan unsur analisis : 
1. Matriks Evalusi Faktor Strategi Internal (IFAS) uraian penilain tentang performa dan kinerja yang mengambarkan faktor kekuatan dan kelemahan dalam mengapai maksud dan tujuan organisasi pasar.

2. Matriks Evaluasi Faktor Strategi Eksternal (EFAS ) di pusatkan terhadap keadaan terkini dan mengarah yang datang dari luar organisasi pasar, namun dapat memberi pengaruh terhadap performa dan kinerja organisasi pasar.

3. Matriks SWOT adalah alat yang dipergunakan dalam menyusun faktor-faktor strategis organisasi pasar. Matriks dijelaskan secara jelas tentang cara ancaman dan peluang eksternal yang terjadi dapat cocok dengan kekuatan dan kelemahan internal yang dimiliki organisasi pasar. Dalam matriks juga mengahasilkan strategi strategi yang dapat di ambil dalam menjalankan tujuan dan maksud organisasi pasar.

\section{PEMBAHASAN}

\subsection{Gambaran Objek Penerapan Ipteks}

Pasar Pinasungkulan Sagerat berkedudukan Di Kelurahan Sagerat Weru 1 Kota Bitung, yang di bangun sejak 2010 dan di resmikan pada 22 Februari 2013 dengan luas sekitar 6 Ha dengan Sarana Prasarana yang sangat menunjang yang terbagi bagi dalam beberapa tempa seperti terdapat : Tempat Jual Ikan Laut, Tempat Jual Daging, Tempat Jual Ikan air tawar, Tempat Jual Ikan kering dan Ikan Asap, Tempat Jual Sayuran, Tempat Jual Buah, Tempat Jual Pakain bekas, Kios Sembako, Kios Grosir, Tempat Potong Hewan, Tempat Transaksi Subuh(Pasar Subuh, melibatkan Pedagang dengan Distributor), WC Umum, Kantor Pasar, Sekretariat Pelayanan Online, Bak Air, Pusat Kesehatan Hewan (PUSKESWAN). Dengan sarana prasarana yang menunjang di dukung juga jumlah pedagang sekitar 150 orang lebih Pasar Pinasunkulan Kota Bitung menjadi Pasar Tradisional dan Pasar dengan Sarana Prasarana lengkap se Indonesia Timur. Berdasarkan ulasan internal dan eksternal maka dapat dimengerti bahwa kekuatan, kelemahan peluang dan ancaman yang dimiliki Pasar Pinasungkulan Sagerat Kota Bitung. alhasil dapat mengetahui faktor penunjang dan faktor penghalang perkembangan Pasar Pinasungkulan Sagerat.

\subsection{Pembahasan}

\section{Strengths (Kekuatan)}

1. Kesesuaian Visi dan Misi. Gambaran visi tentang Pasar Pinasungkulan "menjadi Pasar Tradisional terbaik di kawasan Indonesia Timur" dengan di ikuti misi "untuk pelayanan dan transaksi jual beli nyaman tentram dan bersih".

2. Produk dan dagangan lengkap memadai, yaitu barang dan jasa yang ditawarkan memenuhi kebutuhan konsumen/masyarakat sekitar.

3. Sarana prasarana memadai, tempat dimana pedagang memasarkan produk/dagangan sangat berkualitas dan nyaman untuk penjual dan konsumen melakukan transaksi pembelian.

4. Lokasi strategis. Penempatan posisi Pasar Pinasungkulan Sagerat yang masuk dalam Kelurahan Sagerat Weru 1, Kecamatan Matuari, Kota Bitung sangat strategis karna kebanyakan pembeli/konsumen berasal dari kecamatan Matuari, Girian, Ranowulu juga dari masyarakat Minahasa Utara.

5. Pemasaran bahan pokok secara online. Pengumpulan harga - harga yang di pasarkan dan di upload ke media sosial oleh Asosiasi Pedagang Pasar Pinasungkulan.

6. Kebersihan lingkungan pasar. Daerah pasar yang hygenis, penempatan saluran pembuangan yang sesuai standard dan pembuangan sampah yang teratur dari konsumen maupun pedagang.

7. Harga produk kompetitif, yaitu harga yang ditawarkan sangat bisa dijangkau oleh konsumen sehingga tawar menawar cenderung kurang. 
8. Aksesbilitas, akses masyarakat menuju Pasar Pinasungkulan sangat mudah karna jumlah kepadatan lalu lintas menuju Pasar Pinasungkulan sangat minim dan terdapat terminal kelas $\mathrm{C}$ sebagai sarana persingahan angkutan kota menurunkan masyarakat yang ingin berbelanja.

Weaknesses (Kelemahan)

1. Kualitas dan kuantitas SDM belum memadai. Keterampilan dan pengetahuan pedagang dalam mengelola bisnis dagangan masih minim disebabkan kurangnya pendidikan dan sosialisasi memanajemen bisnis belum maksimal.

2. Belum terselenggara pinjaman dana bagi pelaku usaha. Peminjaman modal bagi para pedagang/penjual masih kurang dikarenakan belum maksimalnya hasil dari penjualan dagangan juga belum terselengara koperasi simpan pinjam di daerah sekitar Pasar Pinasungkulan.

3. Belum maksimal permintaan konsumen, disebabkan transportasi menuju dan keluar dari Pasar Pinasungkulan sangat minim dan para sopir angkutan kota tidak mau melayani rute ke arah Pasar Pinasungkulan dikarenakan jarak dan tarif yang tidak sesuai.

4. Sedikitnya anggaran rehabilitasi pasar, ini disebabkan oleh belum maksimal pemasukan dari kegiatan Pasar Pinasungkulan untuk di setorkan ke Pemerintah Kota Bitung.

5. Keamanan pasar. Jaminan keamanan barang dagangan yang di tinggalkan oleh pedagang/penjual masih sangat rawan karna beberapa kali terjadi kasus pencurian dan pemalakan untuk barang dagangan pedagang.

6. Jaminan kualitas dagangan yang dijual. Kualitas dagangan kurang terkontrol karena belum adanya team dalam pengawasan kualitas dagangan dalam mengontrol dan mencegah barang yang tidak siap dijual dan dipakai konsumen.

\section{Opportunities (Peluang)}

1. Adanya usaha menyediakan pelayanan yang bagus. Lewat pembangunan dan peningkatan Pasar Pinasungkulan diharapkan dapat memenuhi minat masyarakat untuk berbelanja juga dapat menarik pelaku bisnis lainnya dalam melakukan penjualan usaha dagang.

2. Adanya regulasi kebijakan tentang pasar tradisional dan modern. Aturan yang dimaksud bertujuan agar pelaku usaha di pasar Tradisional merasa seimbang melawan mode minat masyarakat dalam kreatifitas harga dagangan.

3. Adanya kebijakan penyegaran pasar tradisional dalam RPJMD. Ditujukan agar transaksi jual beli di Pasar Pinasungkulan bertumbuh dan memberikan pemasukan sesuai target yang di tentukan.

4. Adanya Investasi sekitar Pasar dengan pembangunan KEK (Kawasan Ekonomi Khusus), diharapkan pembangunan KEK yang berdekatan dengan Pasar Pinasungkulan dengan luas $534 \mathrm{Ha}$ dan dapat menarik 10.000+ pekerja bisa meningkatkan pertumbuhan transaksi jual beli di Pasar Pinasungkulan aspek besarnya ialah komoditi bahan pokok adalah kebutuhan utama manusia dalam menunjang kegiatan aktivitas manusia.

5. Tingginya minat untuk berdagang, didasari karena banyak pelaku bisnis yang ingin membuka usaha di Pasar pinasungkulan karna pasar yang nyaman dan strategis.

\section{Threats (Ancaman)}

1. Ramainya pertumbuhan pasar modern di Kota Bitung. Melonjaknya putaran uang di Kota Bitung menyebabkan para pelaku usaha berinvestasi di pasar modern karena fasilitas dalam berbelanja di pasar modern kemungkinan lebih nyaman.

2. Tanggung jawab Pemerintah kota dan Dinas Pasar dalam melaksanakan prosedur. Belum maksimal pergerakan pemkot dan dinas untuk meyakinkan masyarakat dalam berbelanja dan belum maksimal mengusahakan pertumbuhan transaksi di pasar Pinasungkulan. 
3. Pergeseran budaya dan perilaku masyarakat. Dikarenakan globalisasi produk dagangan yang lebih inovatif juga perilaku masyarakat yang memilih tempat berbelanja yang gampang dijangkau dan nyaman.

4. Perilaku pedagang. Kurangnya kuantitas dan kualitas SDM mempengaruhi perilaku pedagang dalam melakukan transaksi penjualan dagangan.

Tabel 1. IFAS Evaluasi Faktor Internal Strategi Pasar Pinasungkulan Sagerat

\begin{tabular}{llccc}
\hline NO & KEKUATAN & BOBOT & RATING & SKOR \\
\hline 1. & Kesesuaian Visi dan Misi & 0.50 & 1 & 0.50 \\
2. & Produk dan Dagangan lengkap memadai & 0.50 & 2 & 1.00 \\
3. & Sarana Prasarana Memadai & 1.00 & 4 & 4.00 \\
4. & Lokasi Strategis & 1.00 & 4 & 4.00 \\
5. & Pemasaran Bahan Pokok secara Online & 0.25 & 2 & 0.50 \\
6. & Kebersihan Lingkungan Pasar & 0.75 & 2 & 1.50 \\
7. & Harga Produk Kompetitif & 0.25 & 3 & 0.75 \\
8. & Aksesbilitas TOTAL & 0.75 & 4 & 3.00 \\
& $\quad \mathbf{5 . 0 0}$ & $\mathbf{2 2}$ & $\mathbf{1 5 . 2 5}$ \\
& $\quad$ & & \\
\hline & KELEMAHAN & BOBOT & RATING & SKOR \\
\hline 1. & Kualitas dan Kuantitas SDM belum memadai & 1.00 & 2 & 2.00 \\
2. & Belum maksimal permintaan konsumen & 0.75 & 3 & 1.50 \\
3. & Sedikitnya Anggaran Rehabilitasi Pasar & 0.75 & 2 & 1.50 \\
4. & Belum terselenggara pinjaman dana bagi & 0.25 & 2 & 0.50 \\
& pelaku usaha & & & \\
5. & Kurangnya Konsumen dalam berbelanja & 1.00 & 4 & 4.00 \\
6. & Keamanan Pasar & 0.75 & 3 & 2.25 \\
7. & Jaminan Kualitas Dagangan yang dijual & 0.50 & 2 & 1.00 \\
$\quad$ TOTAL & $\mathbf{5 . 0 0}$ & $\mathbf{1 8}$ & $\mathbf{1 2 . 7 5}$ \\
\hline
\end{tabular}


Tabel 2. EFAS Evaluasi Faktor Eksternal Strategi Pasar Pinasungkulan Sagerat NO PELUANG BOBOT RATING SKOR

1. Adanya usaha menyediakan pelayanan yang bagus

2. Adanya regulasi kebijakan tentang Pasar tradisional dan modern

3. Adanya kebijakan Penyegaran pasar Tradisional dalam RPJMD
1.00

1.00

1.00

1.00

1.00

5.00
3.00

2.00

$2 \quad 2.00$

$2 \quad 2.00$

4. Adanya Investasi sekitar Pasar dengan pembangunan KEK (Kawasan Ekonomi Khusus)

5. Tingginya minat untuk berdagang

TOTAL

\section{ANCAMAN}

1. Ramainya pertumbuhan pasar Modern di Kota Bitung

2. Tanggung jawab Pemerintah kota dan Dinas Pasar dalam melaksanakan prosedur

3. Pergeseran budaya dan perilaku masyarakat

4. Perilaku pedagang

TOTAL

\section{BOBOT RATING SKOR}

$\begin{array}{lll}0.50 & 2 & 1.00\end{array}$

$\begin{array}{lll}0.50 & 2 & 1.00\end{array}$

$\begin{array}{lll}0.25 & 2 & 0.50\end{array}$

$\begin{array}{lll}0.75 & 2 & 1.50\end{array}$

$\begin{array}{lll}1.00 & 8 & 4.00\end{array}$


GAMBAR MATRIKS SWOT

\section{KEKUATAN}

INTERNAL 1) Kesesuaian visi dan misi

2) Produk dan dagangan lengkap memadai

3) Sarana prasarana memadai

4) Lokasi strategis

5) Pemasaran bahan pokok secara online

6) Kebersihan lingkungan pasar

7) Harga produk kompetitif

8) Aksesbilitas

\section{KELEMAHAN}

1) Kualitas dan kuantitas SDM belum memadai

2) Belum terselenggara pinjaman dana bagi pelaku usaha

3) Belum maksimal permintaan konsumen

4) Sedikitnya anggaran rehabilitasi pasar

5) Keamanan pasar

6) Jaminan kualitas dagangan yang dijual

\section{PELUANG}

1) Adanya upaya untuk memberikan pelayanan yang lebih baik

2) Adanya regulasi kebijakan tentang Pasar tradisional dan modern

3) Adanya kebijakan Penyegaran pasar tradisional dalam RPJMD

4) Adanya Investasi sekitar Pasar dengan pembangunan KEK (Kawasan Ekonomi Khusus

5) Tingginya minat untuk berdagang

\section{ANCAMAN}

1) Ramainya pertumbuhan pasar tradisional di Kota Bitung

2) Tanggung jawab Pemerintah kota dan Dinas Pasar dalam melaksanakan prosedur

3) Pergeseran budaya dan perilaku masyarakat

4) Perilaku pedagang

\section{STRATEGI WO}

$\mathrm{W} 1+\mathrm{W} 2+\mathrm{W} 3+\mathrm{O} 2+\mathrm{O} 3+\mathrm{O} 5$

Kerjasama antara pengelola pasar Pinasungkulan, pedagang dan koperasi

Hasil dari analisis matriks SWOT pada gambar MATRIKS SWOT menghasilkan alternatif strategi dalam pengembangan Pasar Pinasungkulan Sagerat, yaitu :

1. Strategi SO. Agar memperbarui manajemen pengelolaan Pasar Pinasungkulan Sagerat yang telah diterapkan dengan maksud mengerakan kegiatan antar pelaku usaha dan konsumen dan kegiatan pengembangan pasar oleh pemerintah.

2. Strategi ST. Promosi yang dilakukan secara lisan atau melalui media massa/media sosial untuk mempromosikan dagangan dan promosi melalui pengadaan event,lomba,acara oleh pemerintah atau pelaku usaha dengan tujuan dapat meningkatkan jumlah pengunjung dalam bertransaksi jual beli di Pasar Pinasungkulan Sagerat. 
3. Strategi WO. Strategi yang digunakan adalah kerjasama pengelola Pasar Pinasungkulan Sagerat, pelaku usaha, dan peminjam modal dalam memasarkan barang produk dan jasa yang dihasilkan agar dapat diminati masyarakat yang datang di Pasar Pinasungkulan Sagerat.

4. Strategi WT. Pengarahan yang diberikan kepada pelaku usaha dan pedagang ialah pentingnya pengetahuan dalam mengelola barang produk yang ditawarkan, menjaga kebersihan dalam lingkungan pasar, kreatifitas penataan barang produk dan pengetahuan tentang barang produk yang berbahaya bagi masyarakat.

\section{KESIMPULAN DAN SARAN}

\subsection{Kesimpulan}

Pengaruh Faktor internal dan faktor eksternal terhadap keberadaan Pasar Pinasungkulan, Sagerat Weru 1, Kecamatan Matuari yaitu faktor internal terdiri dari kesesuaian visi dan misi,produk dan dagangan lengkap memadai,sarana prasarana memadai, lokasi strategis,pemasaran bahan pokok secara online,kebersihan lingkungan pasar, harga produk kompetitif,aksesbilitas,kualitas dan kuantitas SDM belum memadai, Belum terselenggara pinjaman dana bagi pelaku usaha,belum maksimal permintaan konsumen,sedikitnya anggaran rehabilitasi pasar,keamanan pasar,jaminan kualitas dagangan yang dijual. Sedangkan, faktor eksternal yaitu adanya usaha menyediakan pelayanan yang bagus, adanya regulasi kebijakan tentang Pasar tradisional dan modern,adanya kebijakan penyegaran pasar tradisional dalam RPJMD, adanya investasi sekitar Pasar dengan pembangunan KEK (Kawasan Ekonomi Khusus),tingginya minat untuk berdagang,ramainya pertumbuhan pasar tradisional di Kota Bitung, Tanggung jawab Pemerintah kota dan Dinas Pasar dalam melaksanakan prosedur,pergeseran budaya dan perilaku masyarakat,perilaku pedagang. Alternatif strategi pengembangan Pasar Pinasungkulan, Sagerat Weru 1, Kecamatan Matuari yaitu strategi "Memperbaharui manajemen pasar Pinasungkulan Sagerat", "Peningkatan terhadap promosi pasar tradisional Pinasungkulan", "Kerjasama antara pengelola pasar Pinasungkulan, pedagang dan koperasi" dan"pengarahan untuk para pedagang".

\subsection{Saran}

Untuk Pihak pengelola Pasar Pinasungkulan diharapkan dapat mengimplementasikan strategi sesuai dengan analisis SWOT dan bisa mengambil keputusan jangka pendek dan panjang yang tepat agar Pasar Pinasungkulan bisa berjalan sesuai harapan Pemerintah Kota dan Masyarakat Kota Bitung sebagai Pasar tradisional terlengkap di Kawasan Indonesia Timur. Untuk Pemerintah Kota Bitung, hendaknya melakukan promosi dan sosialisasi dalam pemberdayaan dan pengenalan informasi,aktivitas,keunggulan yang ada dalam Pasar Pinasungkulan Sagerat juga terkait transportasi angkutan kota agar lebih di efektivkan pergerakan trayek menuju ke Pasar Pinasungkulan. Untuk Dinas Pasar Kota Bitung lebih giat dalam mewujudkan rencana dan visi misi dari Pasar Pinasungkulan Sagerat. Untuk pedagang Pasar Pinasungkulan lebih dapat kreatif dalam melakukan usaha bisnis seiring perkembangan dunia.

\section{DAFTAR PUSTAKA}

Rangkuti,F ( 2001). Analisis SWOT: Panduan Hitung IFAS, EFAS, SFAS, Jakarta

David, Fred R., (2006). Manajemen Strategis. Edisi Sepuluh,Pencetak Salemba Empat, Jakarta

Rangkuti, F. (2006), Analisis SWOT : Teknik Membedah Kasus Bisnis, Penerbit PT Gramedia Pustaka Utama ; Jakarta

Iskandar. (2008). Metodologi Penelitian Pendidikan dan Sosial (Kuantitaif dan Kualitatif). Jakarta 
Rangkuti, F. (2002). Analisis SWOT Teknik Membedah Kasus Bisnis. Jakarta : PT. Gramedia Pustaka Utama.

Ritzer, George. (2007) Teori Sosiologi Modern, Prenada media Group, Jakarta

Engel, F.J (1994), Perilaku Konsumen, Edisi Keenam (terjemahan). Jakarta: Binarupa Aksara.

Sumlang, H interview. (2018). Kutipan Informasi statistik Pasar Pinasungkulan Sagerat. Kepala Pasar Pinasungkulan Sagerat

Pinontoan, J interview.(2018). Kutipan Informasi Tentang Pasar Pinasungkulan Sagerat. Ketua Asosiasi Pasar Pinasungkulan Sagerat

Lamalo, E interview. (2018). Kutipan informasi distribusi barang ke Pasar Pinasungkulan Sagerat. Distributor pangan Pasar Pinasungkulan Sagerat

Waworuntu, S interview. (2018). Kutipan informasi transaksi di Pasar Pinasungkulan Sagerat. Pedagang Pasar Pinasungkulan Sagerat

Rumengan, L interview. (2018) Kutipan Informasi Penilain Konsumen. Masyarakat Kota Bitung 